\title{
Thinking 3D: Leonardo to the Present
}

Bodleian Libraries (Oxford), 2019-2020

\section{Katie Jakobiec}

\section{(2) OpenEdition}

\section{Journals}

Electronic version

URL: http://journals.openedition.org/artefact/5933

DOI: $10.4000 /$ artefact.5933

ISSN: 2606-9245

Publisher:

Association Artefact. Techniques histoire et sciences humaines, Presses universitaires du Midi

\section{Printed version}

Date of publication: 15 July 2020

Number of pages: $267-271$

ISBN: 978-2-8107-0691-4

ISSN: 2273-0753

Electronic reference

Katie Jakobiec, «Thinking 3D: Leonardo to the Present », Artefact [Online], 12 | 2020, Online since 21 December 2020, connection on 23 December 2020. URL : http://journals.openedition.org/artefact/ 5933 ; DOI : https://doi.org/10.4000/artefact.5933

\section{(c) (i) (2) $\Theta$}

Artefact, Techniques, histoire et sciences humaines est mise à disposition selon les termes de la Licence Creative Commons Attribution - Pas d'Utilisation Commerciale - Pas de Modification 4.0 International. 


\section{Thinking 3D: Leonardo to the Present}

Bodleian Libraries (Oxford), 2019-2020

7 The Portrait of Luca Pacioli with a Student (1495), reproduced on the first wall of the exhibition space, sets the mood and the intellectual climate of Thinking 3D: Leonardo to the Present, an exhibition held at the Bodleian Libraries in Oxford from March 21, 2019 until February 9, 2020. In the painting, Pacioli, a mathematician and teacher of Leonardo da Vinci and Albrecht Dürer, stands in a dimly lit study with one hand on an open book and the other holding a stick, pointing to a geometric diagram drawn on a slate tablet with 'Euclides' inscribed on its side. His student stands next to him addressing the viewers with his gaze, but Pacioli's attention is focused on the hanging solid and its connection to the objects presented on the table before him. The curators, Laura Moretti and Daryl Green, took advantage of this composition by bringing an actual table into the exhibition space and displaying upon it the objects of a geometer, merging Pacioli's space with the visitor's. The visitor becomes a modern-day student of Pacioli, invited to hold in their hand a dodecahedron (a polyhedron with twelve flat faces) or a rhombicuboctahedron (a convex solid consisting of eighteen square and eight triangle faces) and touch several other examples of a mathematician's instruments. Moretti and Green thus not only demonstrate but also deploy the pedagogical strategy that forms the exhibition's focal point : the idea that three-dimensional objects form the basis for two-dimensional visual analytic reasoning and the transmission of knowledge, and vice versa.

The exhibition coincides with the $500^{\text {th }}$ anniversary of Leonardo's death and connects the Renaissance man with Pacioli, for whose De divina proportione

95 Katie Jakobiec, « Thinking 3D: Leonardo to the Present. Bodleian Libraries (Oxford), 2019-2020 », Artefact, 12, 2020, p. 267-271. 
(1508) Leonardo made 60 drawings that were turned into woodcuts. One of these, a drawing of an 'elevated' icosidodecahedron (a polyhedron with twenty triangular faces and twelve pentagonal faces), is one of five of Leonardo's pieces featured in the exhibition (Fig. 1). Thinking 3D does not, however, concentrate solely on Leonardo and the Renaissance period, though that era no doubt presents a crucible for changes in rendering space utilizing perspective, new techniques of modelling form, and even the introduction of the printing press in the Western world, all of which had an impact on the illustrated book. Rather, the exhibition presents a chronological overview of the need to transmit complex three-dimensional ideas in two-dimensional media, beginning with Euclid's Elements $\left(4^{\text {th }}-3^{\text {rd }}\right.$ century $\mathrm{BCE}$ ) and continuing through the present.

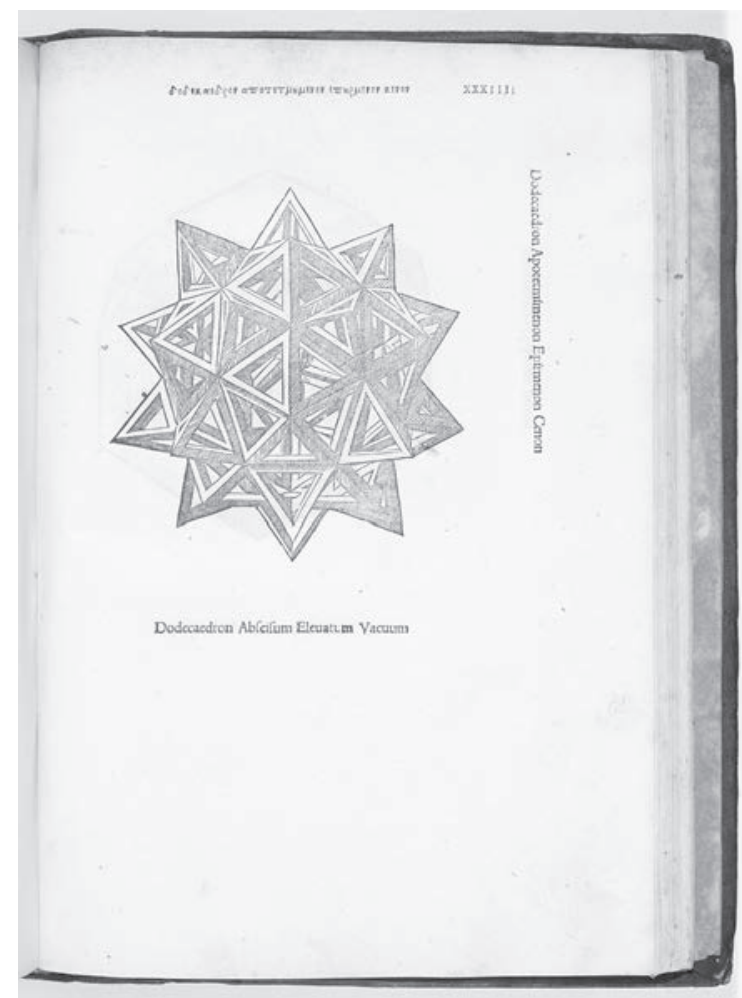

Fig. 1 - Leonardo da Vinci's drawing of an 'elevated' icosidodecahedron, featured in Luca Pacioli's De divina proportione, Venice, 1509

Arch. B d.24 (2)

(c) Bodleian Library, University of Oxford 
The varied and widespread application of the desire to represent 3D in two dimensions is presented in the context of four selected disciplines : geometry, architecture, anatomy and astronomy. Geometry, of course, is the foundational discipline that allows complex bodies, biological and cosmic, to be measured and understood. Architecture, too, especially in the case of such complex stereotomic works as vaults and stairs requires that a series of shapes be worked out and fit together into a whole on the page before being constructed in the real world. With these categories, the curators rein in the endless potential and applicability of three-dimensional thinking ; excluding objects like machines, they opt for the elegant coherence of repetition, focusing on designs of stairs and centrally planned buildings, pages displaying the juxtaposition of text and image, and the four island tables that resonate with those four main disciplines.

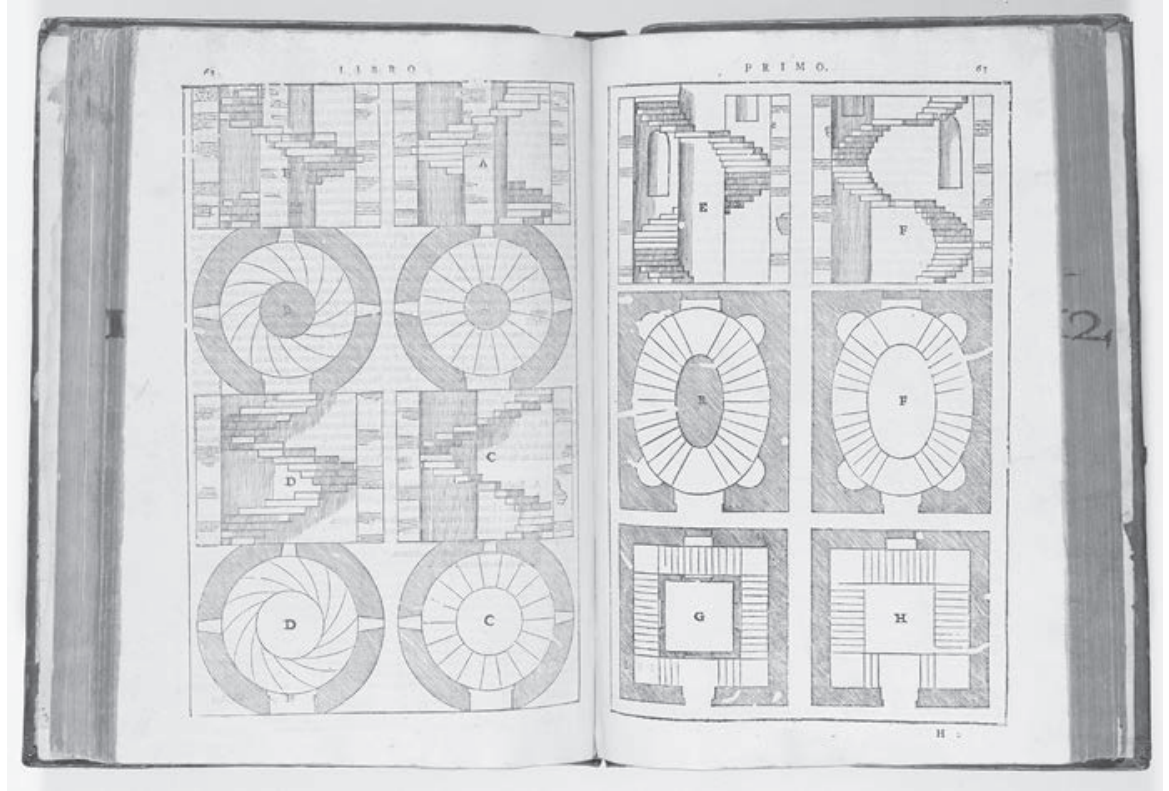

Fig. 2. - Andrea Palladio, I Quattro libri dell'architettura, Venice, 1601

C. 8.12(2) Art

(c) Bodleian Library, University of Oxford

The interplay between three- and two-dimensional modes is at the heart of Thinking $3 D$ and the exhibit clearly articulates the dialogue between the two, disclosing that each informs the other in the working out and working 
through of complex problems. It is also evident that similar techniques are used across different disciplines, adapted for particular purposes in each. For example, Vesalius's De humani corporis fabrica (1543) exposes the inner workings of the human body through illustrating bodies with their skin folded away. The book includes two sheets for the reader-user to cut out and construct 3D models or manikins. Architectural diagrams similarly dissect buildings through cross sections, elevations, and floor plans, informing the viewer how structures are designed and put together, as Andrea Palladio's Four Books on Architecture (1570) makes explicit (Fig. 2). Indeed, the word fabrica - applied interchangeably to architecture, machines, and anatomy-highlights the interconnections of structure and facture.

The exhibition emphasises the idea that "thinking 3D" is an embodied process, requiring the use of the mind and the hand (or, indeed, the mindful hand). Several of the works displayed show that even the two-dimensional mode of the page can, at times, be neither flat nor static. Dynamism and animation come by way of the objecthood of the book itself, the insertion of cut-outs or for example, the glued-in solids intended to be unfolded and popped off the two-dimensional page in Henry Billingsley's English translation of Euclid (1570) (Fig. XXXV, colour plates). Perhaps the most striking examples are multi-layered anatomical books - the so-called 'flap anatomies' - that invite the reader-user to unfold paper flaps and perform armchair autopsies on the depicted human bodies (Fig. XXXVI, colour plates). These examples show that knowledge-its production, communication, and acquisition-requires not only an optic but also a haptic engagement with objects, the addition of the latter enabling a deeper investigation into how things are made, and thus, how they are. As such, the pieces selected for Thinking $3 D$ highlight the multi-dimensional aspect of didacticism, communication that entails the transfer of ideas and forms across space and time (e.g. the work of Palladio), as well as the translation of knowledge into different languages and for different audiences.

Thinking 3D: Leonardo to the Present provides an experience at once physical and intellectual, placing the visitor within a long and ongoing history of communication : the challenge of transmitting knowledge alongside the drive to understand and capture the world as we know it, seeking always to better represent abstract concepts. The theme of the exhibition is aptly reflected in its curatorial strategies, effectively demonstrating the role of the viewer-user in unfolding the experience of learning. Further questions 
are raised, thus, on the basis of personal experience: is dimension itself the only element at stake? What roles are played by scale, material, and portability? Overall, Thinking $3 D$ deftly explores the entangled domains of art, science, and pedagogy, inspiring inquiry as the very construction of knowledge itself.

\author{
Katie Jakobiec \\ University of Toronto
}

